\title{
Neuregulin-1 protects cardiac function in septic rats through multiple targets based on endothelial cells
}

\author{
WEN KANG ${ }^{1}$, YUE CHENG ${ }^{2-4}$, FANG ZHOU ${ }^{1}$, LONG WANG ${ }^{1}$, LIANG ZHONG $^{5}$, \\ HAI TAO $\mathrm{LI}^{6}$, XI WANG ${ }^{2-4}$, SONG DANG ${ }^{2-4}$ and XIN WANG ${ }^{2-4}$
}

\begin{abstract}
Departments of ${ }^{1}$ Anesthesiology and ${ }^{2}$ Cardiology, Renmin Hospital of Wuhan University; ${ }^{3}$ Department of Cardiology, Cardiovascular Research Institute, Wuhan University; ${ }^{4}$ Department of Cardiology, Hubei Key Laboratory of Cardiology; ${ }^{5}$ Department of Anesthesiology, Wuhan Medical and Healthcare Center for Women and Children, Wuhan, Hubei 430060;

${ }^{6}$ Department of Cardiology, Hainan General Hospital, Haikou, Hainan 570100, P.R. China
\end{abstract}

Received April 11, 2019; Accepted June 28, 2019

DOI: $10.3892 / \mathrm{ijmm} .2019 .4309$

\begin{abstract}
The primary mechanism underlying sepsis-induced cardiac dysfunction is loss of endothelial barrier function. Neuregulin-1 (NRG-1) exerts its functions on multiple targets. The present study aimed to identify the protective effects of NRG-1 in myocardial cells, including endothelial, anti-inflammatory and anti-apoptotic effects. Subsequent to lipopolysaccharide (LPS)-induced sepsis, rats were administered with either a vehicle or recombinant human NRG-1 (rhNRG-1; $10 \mu \mathrm{g} / \mathrm{kg} / \mathrm{day}$ ) for one or two days. H9c2 cardiomyoblasts were subjected to LPS $(10 \mu \mathrm{g} / \mathrm{ml})$ treatment for 12 and $24 \mathrm{~h}$ with or without rhNRG-1 $(1 \mu \mathrm{g} / \mathrm{ml})$. Survival rates were recorded at $48 \mathrm{~h}$ following sepsis induction. The hemodynamic method was performed to evaluate cardiac function, and myocardial morphology was observed. Von Willebrand Factor levels were detected using an immunofluorescence assay. Serum levels of tumor necrosis factor $\alpha$, interleukin-6, intercellular cell adhesion molecule-1 and vascular endothelial growth factor were detected using an enzyme-linked immunosorbent assay; the reductase method was performed to detect serum nitric oxide levels. Apoptosis rates were determined using terminal deoxynucleotidyl transferase dUTP nick end labeling staining. Ras homolog family member A (RhoA) and Rho-associated protein kinase 1 (ROCK1) protein levels were assessed using western blotting. Transmission electron microscopy was used to observe endothelial cells and myocardial
\end{abstract}

Correspondence to: Professor Long Wang, Department of Anesthesiology, Renmin Hospital of Wuhan University, 9 Zhangzhidong Road, Wuhan, Hubei 430060, P.R. China

E-mail: wanglongwhu@163.com

Professor Xi Wang, Department of Cardiology, Renmin Hospital of Wuhan University, 9 Zhangzhidong Road, Wuhan, Hubei 430060, P.R. China

E-mail: xiwangwhu@163.com

Key words: sepsis, cardiac dysfunction, neuregulin-1, endothelial cells, ras homolog family member A/Rho-associated protein kinase ultrastructure changes. Results revealed that NRG-1-treated rats displayed less myocardial damage compared with sham rats. NRG-1 administration strengthened the barrier function of the vasculature, reduced the secretion of endothelial-associated biomarkers and exerted anti-inflammatory and anti-apoptotic effects. In addition, NRG-1 inhibited RhoA and ROCK1 signaling. The results revealed that NRG-1 improves cardiac function, increases the survival rate of septic rats and exerts protective effects via multiple targets throughout the body. The present results contribute to the development of a novel approach to reverse damage to myocardial and endothelial cells during sepsis.

\section{Introduction}

Sepsis refers to 'life-threatening organ dysfunction due to a dysregulated host response to infection' (1). The heart is one of the most frequently affected organs during sepsis, and the damage is primarily manifested in the structure and function of cardiac endothelial cells (ECs) (2). ECs are widely distributed throughout the body (3). ECs function as protective barriers of blood vessels and are involved in apoptosis, shedding, permeability changes and uncontrolled secretion of various cytokines and inflammatory factors (3). Endothelial damage and dysfunction is characterized by enhanced inflammation and reduced nitric oxide (NO) bioavailability $(4,5)$.

Dysfunction in the ECs determines the occurrence and development of sepsis and is therefore the pathological basis for sepsis (2). Sepsis and multiple organ dysfunction (MODS) caused by the dysfunction of ECs is usually accompanied by the following four events: i) Changes in vascular endothelial permeability and loss of barrier function; ii) changes in the blood levels of EC-associated biomarkers, including intercellular adhesion molecule 1 (ICAM-1), vascular endothelial growth factor (VEGF) and Von Willebrand Factor (vWF); iii) over-activation of the inflammatory response; and iv) NO levels influencing the blood supply in the myocardium and the contraction and diastolic function of ECs (6).

Neuregulin-1 (NRG-1) is a member of the epidermal growth factor family (7). NRG-1 receptors include epidermal growth factor receptor (ErbB)1, ErbB2, ErbB3 and ErbB4, the 
last three types all being associated with EC protection (7). NRG-1/ErbB signaling pathways are involved in the regulation of EC migration, proliferation, survival and adhesion (8). One previous study revealed that NRG-1 overexpression exerts cardioprotective effects against ischemic injury in cultured cardiomyocytes (9). NRG-1/ErbB signaling may be regulated to attenuate anoxia-induced injuries in cardiac ECs. Furthermore, NRG-1/ErbB signaling has been demonstrated to serve an important function in paracrine and autocrine signaling in the heart, in anti-apoptosis, and in the regulation of myocyte and EC functions (10). In vivo and in vitro experiments have demonstrated that NRG-1 may promote myocardial cell proliferation, inhibit cardiomyocyte apoptosis and protect cardiac ECs; however, the corresponding molecular mechanisms remain yet to be elucidated (11).

NRG-1 exerts protection effect via multiple targets (12). In previous years, it has been reported that NRG-1 may improve myocardial dysfunction caused by sepsis by alleviating inflammation and oxidative stress (12). NRG-1 was demonstrated to increase hemodynamics acutely and improve left ventricular (LV) systolic function (13). However, it has not been reported whether NRG-1 may enhance cardiac function by protecting cardiac vascular ECs from injury in sepsis-induced cardiomyopathy. Considering that the protective mechanism underlying NRG-1 function shares certain common features with the pathway of EC injury in sepsis, it was hypothesized that NRG-1 serves a function in strengthening cardiac function by protecting ECs during sepsis.

\section{Materials and methods}

Animal and specimen collection. Male Sprague Dawley rats (weight, 300-400 g; age, 10 weeks; N=36; Hunan SJA Laboratory Animal Co., Ltd., Hunan, China) were used following one week of acclimation. Briefly, rats were randomly divided into the following three groups: Sham, lipopolysaccharide (LPS) and NRG-1, and each group was divided into two subgroups ( 24 and $48 \mathrm{~h}$ treatment times). Recombinant human NRG-1 (rhNRG-1; cat. no. 10658-H08H; Sino Biological Inc., Wayne, PA, USA) or saline solution was injected into the tail vein at 5 and $24 \mathrm{~h}$ subsequent to model establishment. For the LPS group, the model was established by an intraperitoneal injection of $10 \mathrm{mg} / \mathrm{kg}$ LPS (cat. no. L2880; Sigma Aldrich; Merck KGaA, Darmstadt, Germany); for the sham group, the same volume of saline was injected intraperitoneally at the same time. For the survival assessment, all rats were observed at 6-h intervals for $48 \mathrm{~h}$. At the end of the hemodynamic measurement, blood samples were collected through the inferior vena cava and transferred to sealed tubes. Following 15-20 min, the blood samples were centrifuged at $1,810 \mathrm{x} \mathrm{g}$ for $15 \mathrm{~min}$ at $4^{\circ} \mathrm{C}$ and stored at $-80^{\circ} \mathrm{C}$ until measurement. Subsequent to collecting the blood samples, cardiac tissue samples were selected for biochemical and histopathological analysis. The left ventricular myocardium was transferred to a cryotube and stored at $-80^{\circ} \mathrm{C}$ until Ras homolog family member A (RhoA)/Rho-associated protein kinase 1 (ROCK1) analysis, while the right ventricular myocardium was removed and fixed at $37^{\circ} \mathrm{C}$ for at least $48 \mathrm{~h}$ in $10 \%$ paraformaldehyde solution for histopathological and immunofluorescence analyses. The animal experiments and procedures were ethically approved by the Animal Care and Use Committee of Renmin Hospital of Wuhan University (Wuhan, China). All animals were euthanized with carbon dioxide (displacement rate in the chamber, $20 \%$ volume $/ \mathrm{min}$ ) and then they spines were dislocated to confirm death. All protocols were performed in accordance with the US National Institutes of Health guide for the care and use of Laboratory animals (National Institutes of Health Publication revised in 2011) (14).

Assessment of cardiac function. At 24 or $48 \mathrm{~h}$ following surgery, the rats were anesthetized again with $2 \%$ sodium pentobarbital in saline $(40 \mathrm{mg} / \mathrm{kg}$, intraperitoneally) and placed on a warming pad $\left(37^{\circ} \mathrm{C}\right)$. Following tracheal intubation, the rats were placed on positive-pressure ventilation using a rodent ventilator with a respiratory rate of 70 and a tidal volume six times the weight of the animal. Subsequent to exposing the right carotid artery, a catheter was inserted into the right common carotid artery to quantify the arterial blood pressure using a Labchart system (ADInstruments, Bella Vista, Australia). Once the heart rate and mean arterial pressure (MAP) were measured, the catheter was introduced into the left ventricle via the right carotid artery to monitor the LV systolic pressure (LVSP), LV end-diastolic pressure (LVEDP), LV +dp/dt max (maximum rate of the increase of left ventricular pressure) and LV -dp/dt max (maximum rate of the decrease of left ventricular pressure).

Vascular permeability assay. The structural damage to the cardiac vasculature and vascular permeability were evaluated by measuring vWF expression using immunofluorescence staining. The paraffin sections (5- $\mu \mathrm{m}$-thick) were deparaffinized using conventional xylene and absolute ethanol at $37^{\circ} \mathrm{C}$, placed in a repair box filled with EDTA antigen repair buffer (pH 8.0) and permeabilized with phosphate-buffered saline at $92-96^{\circ} \mathrm{C}$ for $15 \mathrm{~min}$. In this process, excessive evaporation of the buffer was prevented and no occurred. After natural cooling, the slides were placed in PBS (pH 7.4) and washed three times in a decolorizing shaking bed for 5 min each time. The slides were blocked with BSA (cat. no. G5001; Servicebio, Inc., Wuhan, China) for $30 \mathrm{~min}$ at $37^{\circ} \mathrm{C}$. Sections were immunostained by incubation with primary antibodies against vWF (1:200; cat. no. GB11020; Servicebio, Inc.) at $4^{\circ} \mathrm{C}$ overnight, then incubated with CY3-conjugated goat anti-rabbit secondary antibodies (1:300; cat. no. GB21303; Servicebio, Inc.) at $37^{\circ} \mathrm{C}$ for $50 \mathrm{~min}$ and subsequently incubated with DAPI (cat. no. G1012; Servicebio, Inc.) at $37^{\circ} \mathrm{C}$ for $10 \mathrm{~min}$. The slides were photographed using a fluorescence microscope (Nikon Corporation, Tokyo, Japan). The percentage of vWF present on the endothelial lining was calculated for each image. The images were analyzed using ImageJ software (version d 1.47; National Institutes of Health, Bethesda, MD, USA).

Measurement of endothelial-associated and oxidative stress biomarkers. ICAM-1 and VEGF enzyme-linked immunosorbent assay (ELISA) kits (cat. nos. CSB-E04576r and CSB-E04757r, respectively; Cusabio, Wuhan, China) were used to measure the serum levels of the endothelial biomarkers in blood samples, including leukocyte adhesion molecule ICAM-1 and VEGF. The NO contents of the rats in each group were measured following the reductase method using a NO kit 
(cat. no. A012; Jiancheng Bioengineering Institute, Nanjing, China). The assays were all performed according to the manufacturer's protocols. Each treatment and the corresponding control were analyzed in the same run.

Observation of myocardial tissues and cells ultrastructure. The structures of myocardial cells and tissues were observed by transmission electron microscopy and hematoxylin-eosin (H\&E) staining, respectively.

The myocardial tissues were sliced into $1-\mathrm{mm}^{3}$ pieces and fixed with $2.5 \%$ glutaraldehyde in phosphate buffer for $2.5 \mathrm{~h}$ at $4^{\circ} \mathrm{C}$ and then re-fixed in $1 \%$ osmium tetroxide in phosphate buffer for $2 \mathrm{~h}$ at $4^{\circ} \mathrm{C}$. The tissues were dehydrated in a graded series of ethanol solutions $(50,70,80,90.95$ and 100), and then immersed in a mixture of acetone and epoxy resin twice at $37^{\circ} \mathrm{C}(2: 1$ for $3 \mathrm{~h}$ the first time, 1:2 for overnight the second time). Finally, the tissues were embedded in epoxy resin-filled capsules and heated at $70^{\circ} \mathrm{C}$ overnight. Ultrathin sections (60-80 nm) were sliced and observed using a transmission electron microscope (TECNAI G2 20 TWIN; FEI; Thermo Fisher Scientific, Inc., Waltham, MA, USA).

Samples were fixed in $4 \%$ formalin for at least $48 \mathrm{~h}$ at $37^{\circ} \mathrm{C}$. Subsequent to fixation, each tissue sample was processed routinely and embedded in paraffin wax and serially sectioned at $4 \mu \mathrm{m}$ thickness. The sections were stained with $\mathrm{H} \& \mathrm{E}$ at $37^{\circ} \mathrm{C}$ (hematoxylin staining for $5 \mathrm{~min}$ and eosin staining for $3 \mathrm{~min}$ ), and analyzed under an optical microscope (Nikon Corporation); 5-6 fields were photographed randomly under a magnification of $\mathrm{x} 100$.

Apoptosis of myocardial cells analysis. The paraffin sections were deparaffinized, incubated with the rupture solution for $30 \mathrm{~min}$ at $37^{\circ} \mathrm{C}$, and subsequently reagent $1(\mathrm{TdT})$ and reagent 2 (dUTP) were added at a ratio of 2:29 using the terminal deoxynucleotidyl-transferase-mediated dUTP nick end labeling assay kit (cat. no. 11684817910; Roche Diagnostics, Basel, Switzerland). DAPI was used to counterstain the cell nuclei for $5 \mathrm{~min}$ at $37^{\circ} \mathrm{C}$. Images of the sections were observed and captured under an inverted fluorescent microscope under a magnification of $x 400$. The TUNEL kit was used according to the manufacturer's protocol. The apoptosis rate was calculated as the number of apoptotic cells/total number of cells $\times 100 \%$.

Measurement of inflammatory factors. Serum levels of tumor necrosis factor $\alpha$ (TNF- $\alpha$ ) and interleukin-6 (IL-6) were detected by ELISA using TNF- $\alpha$ ELISA kit (cat. no. 88-7340; Thermo Fisher Scientific, Inc.) and IL-6 kit [cat. no. EK3061; MultiSciences (LIANKE) biotech, Co., Ltd., Hangzhou, China]. The protocol was strictly performed according to the manufacturer's protocol.

Cell culture and treatment. H9c2 cardiomyoblasts were purchased from iCell Bioscience Inc. (San Francisco, CA, USA) and were cultured in Dulbecco's modified Eagle's medium (cat. no. SH30021.01; Hyclone; GE Healthcare Life Sciences, Logan, UT, USA) supplemented with $10 \%$ fetal bovine serum (cat. no. 10099-141; Gibco; Thermo Fisher Scientific, Inc.), penicillin (100 U/ml) and streptomycin (100 mg/ml; cat. no. SV30010.01; Hyclone; GE Healthcare Life Sciences). The H9c2 cells were challenged with LPS
$(10 \mu \mathrm{g} / \mathrm{ml})$ at $37^{\circ} \mathrm{C}$ for 24 and $48 \mathrm{~h}$. rhNRG-1 $(1 \mu \mathrm{g} / \mathrm{ml})$ was added to the cells at $5 \mathrm{~h}$ in the NRG-1 group treated with LPS for $24 \mathrm{~h}$, or at 5 and $24 \mathrm{~h}$ in the NRG-1 group treated with LPS for $48 \mathrm{~h}$. The culture medium and cells were collected for western blot analysis.

RhoA and ROCK1 western blot protein analysis. A 10-fold volume of RIPA lysate (cat. no. G2002; Servicebio Inc.) was added $100 \mathrm{mg}$ heart tissues; H9c2 cells were incubated with an appropriate volume RIPA lysate. Heart tissues were homogenized and lysed at $-20^{\circ} \mathrm{C}$ for $60 \mathrm{sec}$ and $\mathrm{H} 9 \mathrm{c} 2$ cells were homogenized and lysed at $-20^{\circ} \mathrm{C}$ for $15 \mathrm{~min}$, the supernatants of lysates were obtained by centrifugation at $12,000 \mathrm{x} \mathrm{g}$ for $0.5 \mathrm{~h}$ at $4^{\circ} \mathrm{C}$. After protein concentration was determined with a BCA protein assay kit (cat. no. G2026; Servicebio, Inc.), aliquots of protein (40 $\mu \mathrm{g}$ per lane) were separated by sodium dodecyl sulfate-polyacrylamide gel electrophoresis on a $12 \%$ gel. Proteins were transferred onto polyvinylidene fluoride membranes (EMD Millipore, Billerica, MA, USA) for $1.5 \mathrm{~h}$, and the membranes were blocked with $5 \%$ nonfat milk in tris-buffered saline with $0.05 \%$ Tween-20 for $1 \mathrm{~h}$ at $37^{\circ} \mathrm{C}$. After being blocked with $5 \%$ non-fat dry milk for $1 \mathrm{~h}$ at $37^{\circ} \mathrm{C}$, the primary antibodies used included polyclonal antibodies for RhoA (dilution 1:1,000; cat. no. 2117S) and ROCK1 (dilution 1:1,000; cat. no. 4035S; both Cell Signaling Technology, Inc., Danvers, MA, USA) at $4^{\circ} \mathrm{C}$ overnight. The membrane was also incubated with GAPDH primary antibodies (dilution 1:10,000; cat. no. GB12002; Servicebio Inc.) at $37^{\circ} \mathrm{C}$ for $30 \mathrm{~min}$. Subsequent to incubation with horseradish peroxidase-conjugated goat anti-rabbit (cat. no. GB23303) or goat anti-rat (cat. no. GB23302) secondary antibodies (dilution 1:3,000). After washing three times with TBST (cat. no. G0001; both Servicebio, Inc.) at $37^{\circ} \mathrm{C}$ for $30 \mathrm{~min}$, the proteins were immersed in enhanced chemiluminescence solution (cat. no. G2014; Servicebio, Inc.) for $1 \mathrm{~min}$ and imaged in a chemical scanner (V300; EPSON, Seiko Epson Corp., Japan). GAPDH was used as a loading control. The bands were analyzed using ImageJ software (version d 1.47).

Statistical analysis. Data were presented as the mean \pm standard deviation and analyzed using SPSS 24.0 software (IBM Corp., Armonk, NY, USA). Multiple groups were analyzed using two-way analysis of variance with Bonferroni's post-hoc test. Survival rates were expressed as the percentage of live animals, and survival curves were generated using the Kaplan-Meier method. Survival assessments were compared using Gehan-Breslow-Wilcoxon tests. $\mathrm{P}<0.05$ was considered to indicate a statistically significant difference.

\section{Results}

Experimental model and survival rates. Rats presented with reduced activity, diarrhea, piloerection and exudation around the eyes at $4 \mathrm{~h}$ after LPS induction. Conversely, the sham group exhibited no detectable signs of disease. The survival rates were evaluated at $48 \mathrm{~h}$ after LPS injection. Rats in the sham group demonstrated a $100 \%$ survival rate $(n=12)$. Rats in the LPS group demonstrated survival rates of $87.5 \%$ (21 out of 24$)$ at $12 \mathrm{~h}$ and $66.7 \%$ (16 of 24 ) at $24 \mathrm{~h}$, which progressively dropped to $50.0 \%$ (14 of 24) at $48 \mathrm{~h}$. The administration of NRG-1 significantly 
increased the survival rate in the NRG-1 group to $83.3 \%$ (20 out of 24) at $48 \mathrm{~h}$ compared with the LPS group (P<0.05; Fig. 1). The above results indicated that NRG-1 effectively abrogated the decrease in survival rate of rats with sepsis.

rhNRG-1 improves cardiac function. Cardiac function was evaluated by invasive hemodynamic measurements at 24 and $48 \mathrm{~h}$ after sepsis induction. LPS-induced sepsis was revealed to significantly alter the indices of cardiovascular performance compared with the sham group $(\mathrm{P}<0.05 ;$ Fig. 2$)$. The differences in heart rate among the three groups were not statistically significant $(\mathrm{P}>0.05)$. Compared with rats in the sham group, the rats in the LPS group exhibited significantly lower values of MAP, LVSP and $\pm \mathrm{dp} / \mathrm{dt}$ max, in addition to increased LVEDP $(\mathrm{P}<0.05)$. By contrast, subsequent to the administration of rhNRG-1, the hemodynamic abnormalities mentioned above were significantly attenuated $(\mathrm{P}<0.05)$. The rats in the $48 \mathrm{~h}$ group exhibited slightly greater improvement in cardiovascular performance compared with the $24 \mathrm{~h}$ group (Table I).

rhNRG-1 decreases cardiac vascular permeability. The vascular endothelium was partially exfoliated and vascular permeability significantly increased in the sepsis group compared with the sham group $(\mathrm{P}<0.05)$; the observed alterations were significantly attenuated in the NRG-1 group $(\mathrm{P}<0.05)$. Staining patterns for $\mathrm{vWF}$ exhibiting respective degrees of damage are illustrated in Fig. 3.

rhNRG-1 influences levels of endothelial and oxidative stress biomarkers. The biomarkers used to evaluate the activation or functional impairment of ECs included ICAM-1 and VEGF. The further sequence of pathogenesis of endothelial dysfunction in sepsis is the overproduction of NO (15). The serum levels of ICAM-1, VEGF and NO in rats in the sepsis group were significantly higher compared with the sham group $(\mathrm{P}<0.05)$, whereas rhNRG-1 treatment was able to prevent these increases, and ICAM-1 and NO levels were significantly decreased at $48 \mathrm{~h}$ of treatment compared with $24 \mathrm{~h}$ (Fig. 4; Table II).

rhNRG-1 ameliorates cardiac injury in septic rats. Based on the histological results. rats in the LPS group exhibited disorderly arranged myocardial fibers, unclear cell boundaries, interstitial edema and inflammatory cell infiltration when compared with the rats in the sham group (Fig. 5A). Cytological results indicated that at $24 \mathrm{~h}$ after LPS-induced sepsis, the distances between the myofibrils of the myocardium were widened and even broken or dissolved, mitochondrial swelling of the volume of mitochondria increased and the electron density of the matrix decreased; and in addition, matrix particles decreased or disappeared, the cristae shortened, were decreased and their edges shifted and the damage was aggravated with the progression of sepsis (Fig. 5B). rhNRG-1 treatment markedly reduced the aforementioned changes.

rhNRG-1 reduces cardiac apoptotic cells in septic rats. LPS-induced sepsis significantly increased the percentage of apoptotic cardiomyocytes compared with the sham group $(\mathrm{P}<0.05)$. The observed increase was significantly attenuated in the NRG-1 group $(\mathrm{P}<0.05)$; thus, overall, treatment

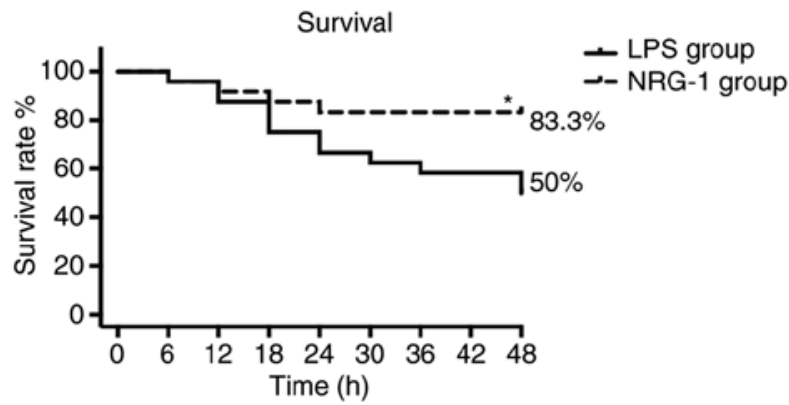

Figure 1. Survival rate of rats that had been treated with LPS and NRG-1 were estimated for $48 \mathrm{~h}$ and analyzed using the Kaplan-Meier plots and compared using the Gehan-Breslow-Wilcoxon tests. ${ }^{*} \mathrm{P}<0.05$ vs. LPS group. LPS, lipopolysaccharide; NRG-1, neuregulin-1.

with rhNRG-1 exhibited an anti-apoptotic effect (Fig. 6). The percentage of apoptotic cells in the LPS $48 \mathrm{~h}$ group were significantly reduced compared with those in the LPS $24 \mathrm{~h}$ group $(\mathrm{P}<0.05)$, However, rats in the 24 and $48 \mathrm{~h}$ groups exhibited no significant differences in the therapeutic effects of rhNRG-1 $(\mathrm{P}>0.05)$

rhNRG-1 suppresses the proinflammatory response. rhNRG-1 is known to exert an anti-inflammatory effect in the nervous system (7). The preliminary experiment in the present study revealed the inhibitory effect of rhNRG-1 on the serum levels of inflammatory cytokines in the septic rat model at $24 \mathrm{~h}$ after sepsis induction. The levels of TNF- $\alpha$ and IL- 6 continued to increase within $48 \mathrm{~h}$ but were partially restored to original levels by rhNRG-1 treatment at $48 \mathrm{~h}$ after sepsis induction (Table III).

rhNRG-1 inhibits the activation of RhoA/ROCK signaling. To investigate whether angiogenic factors are associated with myocardial endothelial protection induced by NRG-1 treatment, the present study examined the RhoA/ROCK signaling systems using western blot analysis in vivo (Fig. 7) and in vitro (Fig. 8). Protein expression levels of RhoA and ROCK1 were revealed to be significantly upregulated in the LPS group compared with those in the sham group $(\mathrm{P}<0.05)$. However, rats in NRG-1 group exhibited a significant reduction in RhoA and ROCK1 protein levels compared with rats in the LPS group $(\mathrm{P}<0.05$; Fig. 7$)$.

To further verify this hypothesis, the present study used H9c2 cardiomyoblasts to demonstrate these mechanisms (Fig. 8). The significantly higher activation of RhoA and ROCK1 signaling were observed in LPS-treated cells compared with the sham group, while NRG-1 significantly inhibited this activation compared with the LPS group $(\mathrm{P}<0.05)$. This result is consistent with the result of the in vivo experiment. In addition, RhoA and ROCK1 proteins were more significantly activated in the $48 \mathrm{~h}$ group compared with the $24 \mathrm{~h}$ group $(\mathrm{P}<0.05)$, and NRG-1 was able to significantly inhibit the activation of RhoA and ROCK in the two groups $(\mathrm{P}<0.05)$.

\section{Discussion}

Over $70 \%$ of all sepsis-associated cases of mortality are attributed to organ failure, in which the function of myocardial 
Table I. Cardiac function indices of rats in each treatment group.

\begin{tabular}{lcccccc}
\hline & HR $(\mathrm{bpm})$ & MAP $(\mathrm{mmHg})$ & LVSP $(\mathrm{mmHg})$ & $\mathrm{LVEDP}(\mathrm{mmHg})$ & $+\mathrm{dP}_{\mathrm{dt}} \max (\mathrm{mmHg} / \mathrm{s})$ & $-\mathrm{dP} / \mathrm{dt} \mathrm{max}_{\operatorname{mmHg} / \mathrm{s})}(\mathrm{mm}$ \\
\hline Sham 24 h & $427.43 \pm 21.70$ & $146.64 \pm 11.01$ & $214.20 \pm 5.12$ & $8.47 \pm 0.33$ & $4,265.60 \pm 41.56$ & $-4,902.61 \pm 13.61$ \\
Sham 48 h & $445.36 \pm 18.12$ & $144.94 \pm 6.98$ & $133.90 \pm 5.23$ & $9.23 \pm 0.38$ & $3,603.92 \pm 33.50$ & $-3,338.87 \pm 125.67$ \\
LPS 24 h & $447.51 \pm 15.29$ & $58.09 \pm 4.12^{\mathrm{a}}$ & $103.55 \pm 6.28^{\mathrm{a}}$ & $12.69 \pm 0.05^{\mathrm{a}}$ & $1,972.14 \pm 18.36^{\mathrm{a}}$ & $-1,776.90 \pm 85.46^{\mathrm{a}}$ \\
LPS 48 h & $427.76 \pm 28.26$ & $53.03 \pm 4.10^{\mathrm{a}}$ & $95.87 \pm 6.22^{\mathrm{a}}$ & $13.91 \pm 0.40^{\mathrm{a}}$ & $2,250.74 \pm 126.44^{\mathrm{a}}$ & $-1,407.43 \pm 87.29^{\mathrm{a}}$ \\
NRG-1 24 h & $437.91 \pm 21.67$ & $109.35 \pm 8.17^{\mathrm{b}}$ & $128.56 \pm 12.98^{\mathrm{b}}$ & $5.72 \pm 0.64^{\mathrm{b}}$ & $4,744.99 \pm 226.84^{\mathrm{b}}$ & $-2,401.84 \pm 92.66^{\mathrm{b}}$ \\
NRG-1 48 h & $390.86 \pm 40.95$ & $111.40 \pm 7.63^{\mathrm{b}}$ & $126.05 \pm 6.69^{\mathrm{b}}$ & $4.16 \pm 0.78^{\mathrm{b}}$ & $3,163.68 \pm 203.58^{\mathrm{b}, \mathrm{c}}$ & $-2,435.89 \pm 116.65^{\mathrm{b}}$
\end{tabular}

Data are presented as the mean \pm standard deviation $(\mathrm{n}=6) .{ }^{\mathrm{a}} \mathrm{P}<0.05$ vs. sham group; ${ }^{\text {b }}<0.05$ vs. LPS group; ${ }^{\mathrm{C}} \mathrm{P}<0.05$ vs. $24 \mathrm{~h}$ group. LPS, lipopolysaccharide; NRG-1, neuregulin-1; HR, heart rate; MAP, mean arterial pressure; LVSP, left ventricular systolic pressure; LVEDP, left ventricular end-diastolic pressure; $\pm \mathrm{dp} / \mathrm{dt}$ max, first derivative of left ventricular pressure.
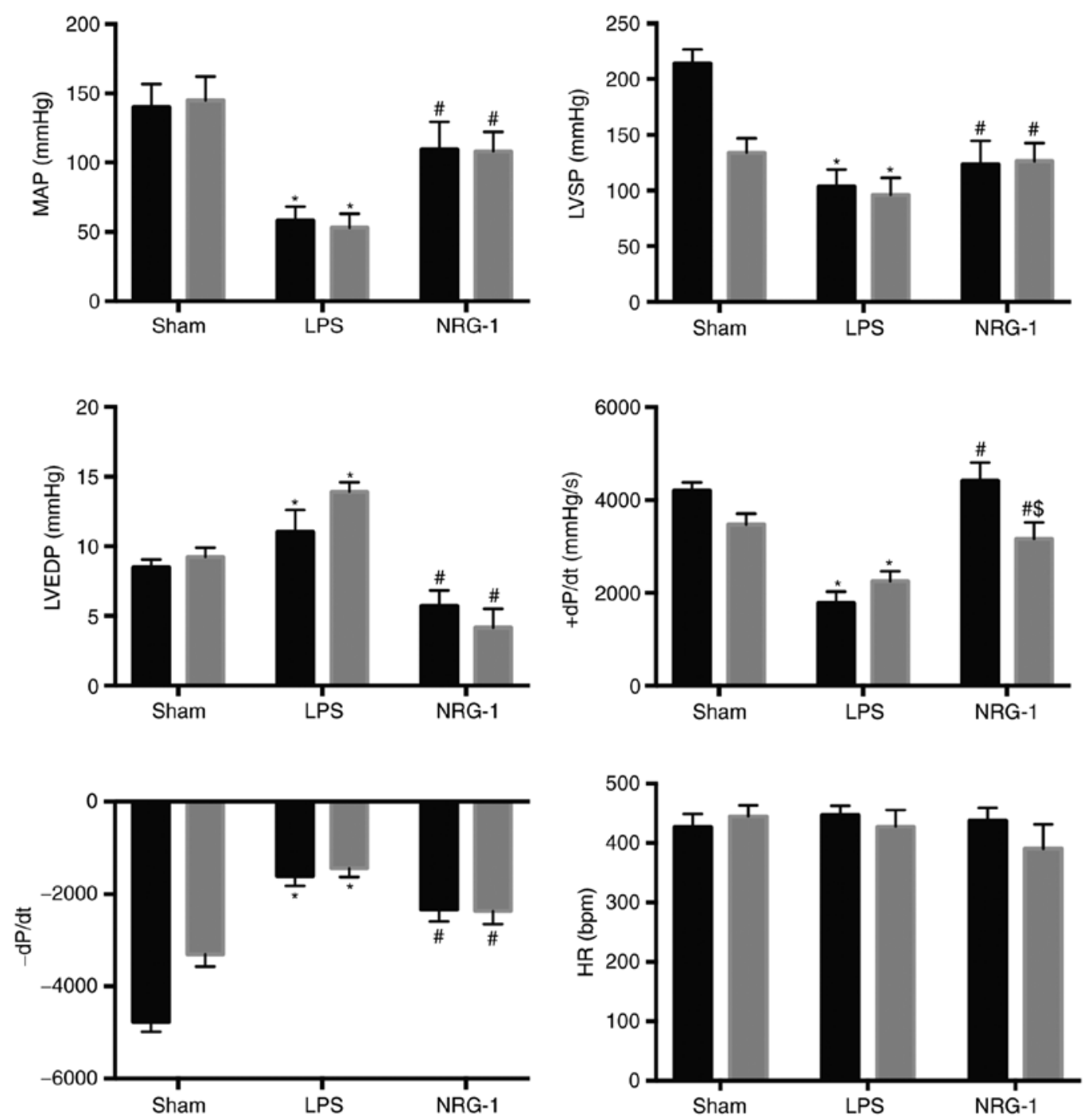

Figure 2. Cardiac function performance at 24 and $48 \mathrm{~h}$ after LPS induction. $\mathrm{n}=6$. Data are presented as the mean \pm standard deviation. " $\mathrm{P}<0.05 \mathrm{vs}$. sham group; ${ }^{\#} \mathrm{P}<0.05$ vs. LPS group; ${ }^{5} \mathrm{P}<0.05$ vs. $24 \mathrm{~h}$ group. LPS, lipopolysaccharide; NRG-1, neuregulin-1; HR, heart rate; MAP, mean arterial pressure; LVSP, left ventricular systolic pressure; LVEDP, left ventricular end-diastolic pressure; $\pm \mathrm{dp} / \mathrm{dt} \max$, first derivative of left ventricular pressure.

dysfunction is widely recognized (16). Changes in endothelial function and vascular tension associated with sepsis inevitably affect cardiac function (17). Endothelial dysfunction is a necessary component of the hemodynamic collapse caused by sepsis. As a result, single drug therapy is often insufficient to effectively reverse the organ dysfunction caused by sepsis (17). Therefore, therapies should be combined with anti-inflammatory and immune regulation and vascular endothelial function 

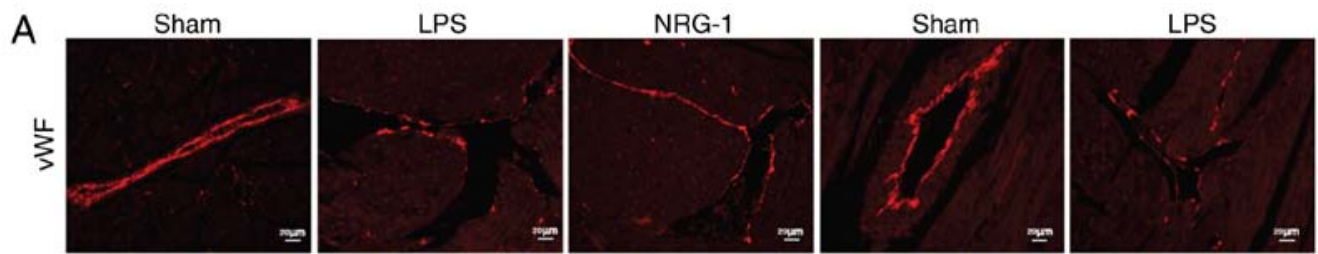

NRG-1
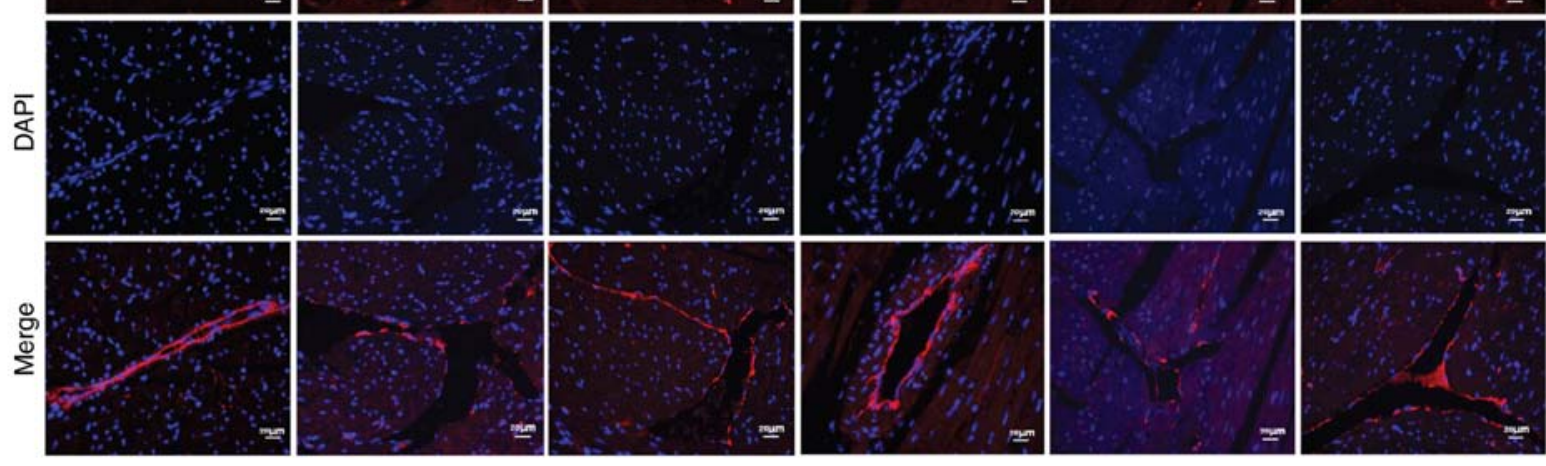

$24 \mathrm{~h}$

$48 \mathrm{~h}$

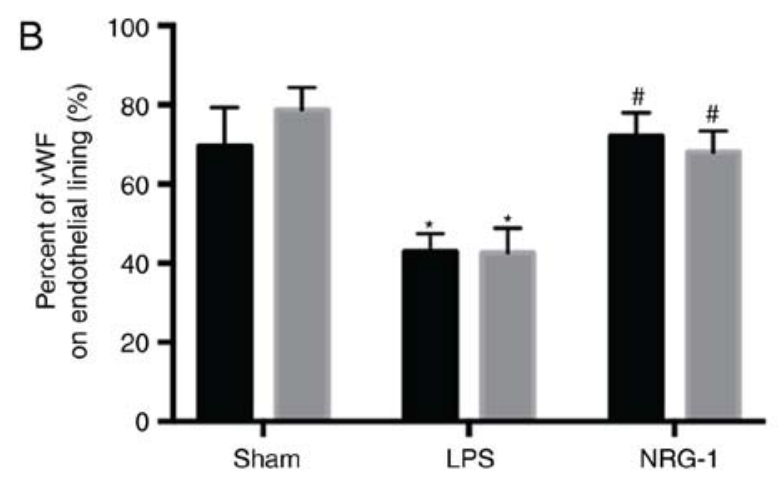

Figure 3. Damage to cardiac endothelial function varied among the individuals in each group. (A) DAPI staining and vWF assay. Red indicates vWF-positive nuclei; blue indicates DAPI signals (magnification, $\mathrm{x} 400, \mathrm{n}=5$, five fields for each specimen). (B) Percentages of vWF present on cardiac vascular endothelial lining for all groups. Data are presented as the mean \pm standard deviation. ${ }^{*} \mathrm{P}<0.05$ vs. sham group; ${ }^{~} \mathrm{P}<0.05$ vs. LPS group. vWF, Von Willebrand Factor; LPS, lipopolysaccharide; NRG-1, neuregulin-1.
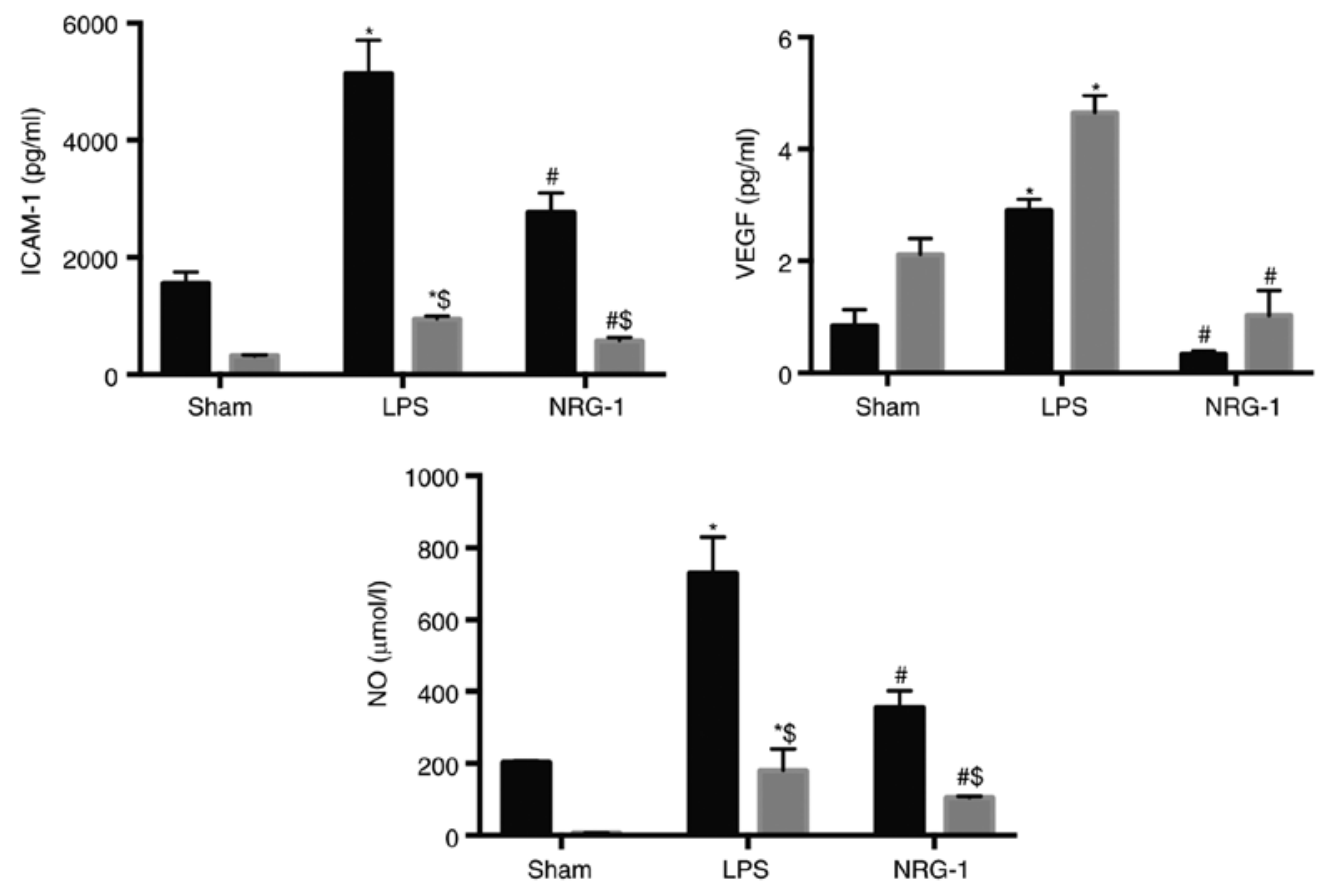

Figure 4. Serum levels of ICAM-1, VEGF and NO in septic rats treated with recombinant human NRG-1. $\mathrm{n}=6$. Data are presented as the mean \pm standard deviation. ${ }^{*} \mathrm{P}<0.05$ vs. sham group; ${ }^{\prime} \mathrm{P}<0.05$ vs. LPS group; ${ }^{\$} \mathrm{P}<0.05$ vs. $24 \mathrm{~h}$ group. ICAM-1, intercellular cell adhesion molecule-1; VEGF, vascular endothelial growth factor; NO, nitric oxide; LPS, lipopolysaccharide; NRG-1, neuregulin-1. 
Table II. Serum levels of ICAM-1, VEGF and NO in rats from each treatment group.

\begin{tabular}{lcrr}
\hline Variables & ICAM-1 $(\mathrm{pg} / \mathrm{ml})$ & VEGF $(\mathrm{pg} / \mathrm{ml})$ & $\mathrm{NO}(\mathrm{pg} / \mathrm{ml})$ \\
\hline Sham $24 \mathrm{~h}$ & $1,564.74 \pm 94.41$ & $0.84 \pm 0.28$ & $203.27 \pm 1.81$ \\
Sham $48 \mathrm{~h}$ & $322.92 \pm 7.92$ & $1.78 \pm 0.61$ & $6.57 \pm 0.38$ \\
LPS $24 \mathrm{~h}$ & $5,139.85 \pm 284.15^{\mathrm{a}}$ & $3.11 \pm 0.04^{\mathrm{a}}$ & $679.05 \pm 78.59^{\mathrm{a}}$ \\
LPS 48 h & $950.41 \pm 25.23^{\mathrm{a}, \mathrm{b}}$ & $4.65 \pm 0.30^{\mathrm{a}}$ & $180.40 \pm 30.08^{\mathrm{a}, \mathrm{b}}$ \\
NRG-1 24 h & $2,772.18 \pm 164.45^{\mathrm{c}}$ & $0.30 \pm 0.04^{\mathrm{c}}$ & $355.14 \pm 23.41^{\mathrm{c}}$ \\
NRG-1 48 h & $578.57 \pm 28.97^{\mathrm{b}, \mathrm{c}}$ & $1.02 \pm 0.45^{\mathrm{c}}$ & $104.67 \pm 2.13^{\mathrm{b}, \mathrm{c}}$ \\
\hline
\end{tabular}

Data are presented as the mean \pm standard deviation $(\mathrm{n}=6)$. ${ }^{\mathrm{a}} \mathrm{P}<0.05$ vs. sham group; ${ }^{\mathrm{b}} \mathrm{P}<0.05 \mathrm{vs}$. $24 \mathrm{~h}$ group; ${ }^{\mathrm{c}} \mathrm{P}<0.05$ vs. LPS group. ICAM-1, intercellular cell adhesion molecule-1; VEGF, vascular endothelial growth factor; NO, nitric oxide; LPS, lipopolysaccharide; NRG-1, neuregulin-1 .

A
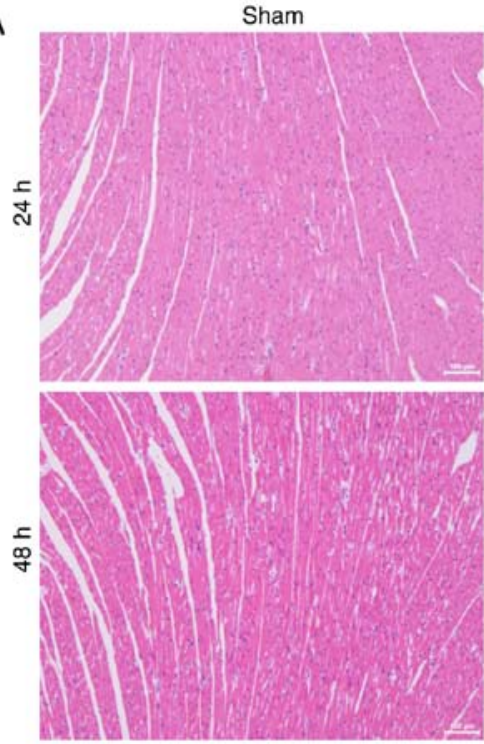

B
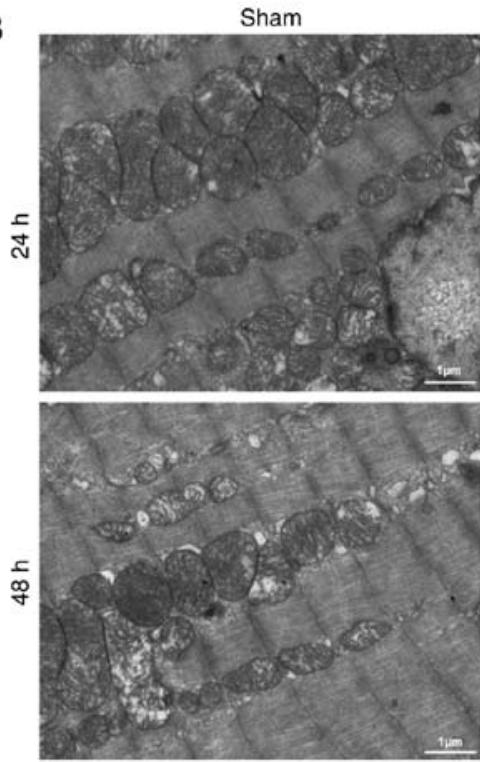

LPS
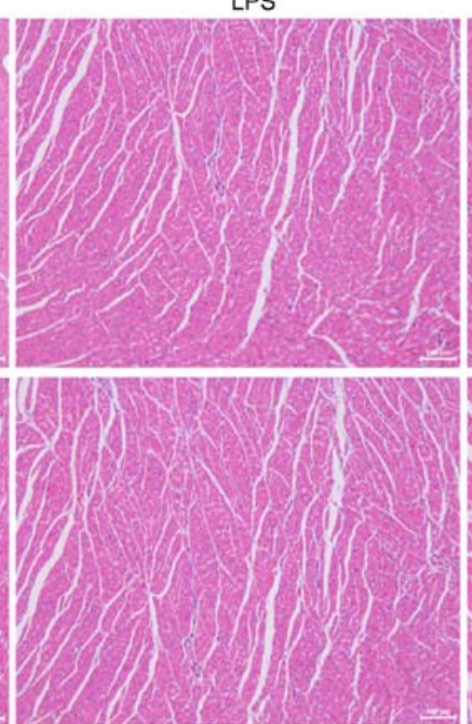

LPS
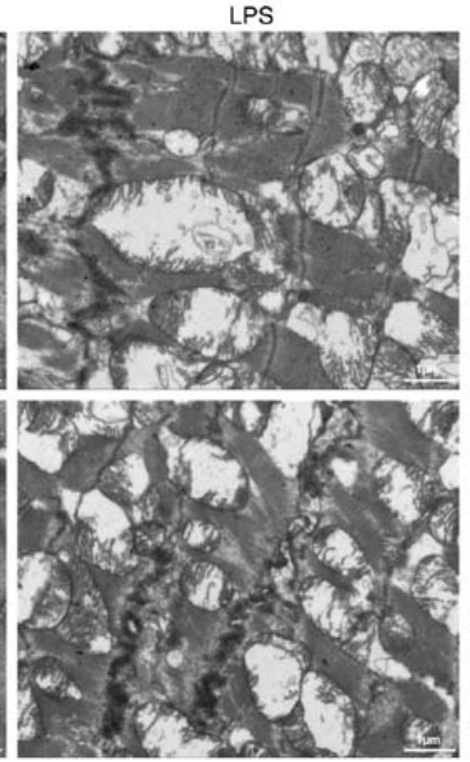

NRG-1

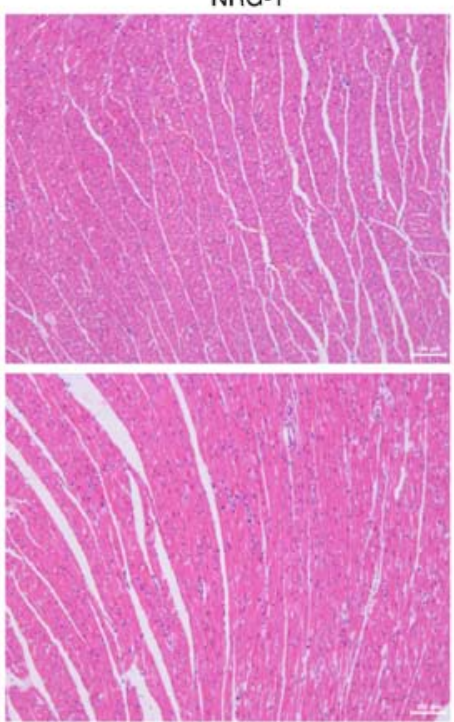

NRG-1
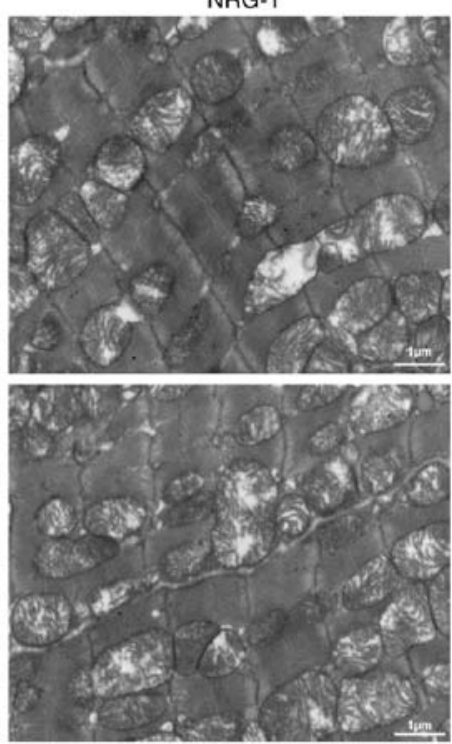

Figure 5. (A) Representative pathological changes in the myocardia of rats at 24 and $48 \mathrm{~h}$ after LPS procedures (haemotoxylin and eosin staining, magnification x100). Sham group had neatly arranged myocardial fibers; in the LPS group, infiltration with inflammatory cells was observed in the myocardium and exhibited the disordered arrangement of myocardial fibers; in the NRG-1 group, a substantial reduction in infiltration with inflammatory cells and myocardial fiber disorderly appeared in the myocardium subsequent to administration with recombinant human NRG-1. The pathological changes in the 48 h group were slightly alleviated compared with those observed in the $24 \mathrm{~h}$ group (bars $=100 \mu \mathrm{m}$ ). (B) Changes in myocardial cells as observed under a transmission electron microscope (magnification, x6,000, bars=1 $\mu \mathrm{m}$ ). LPS, lipopolysaccharide; NRG-1, neuregulin-1. 


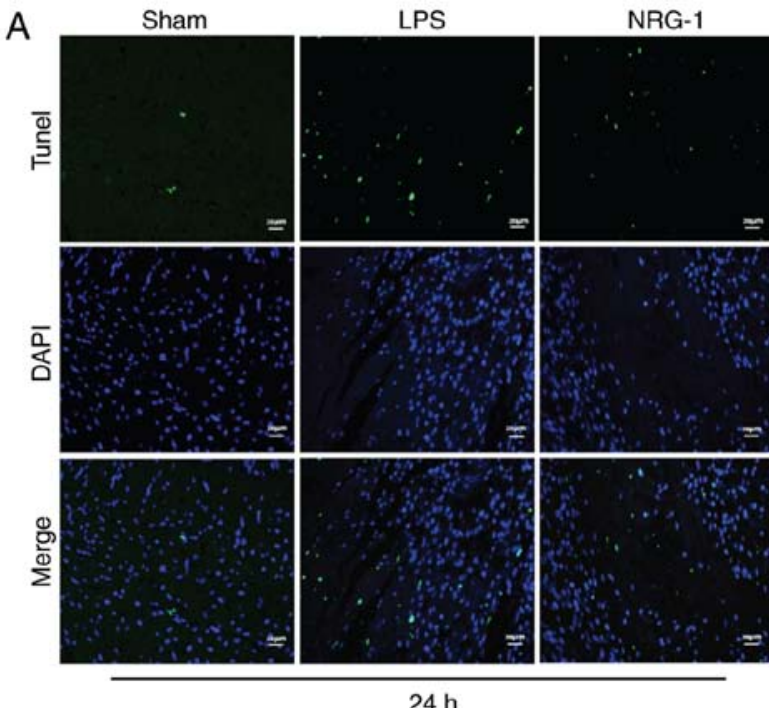

$24 \mathrm{~h}$

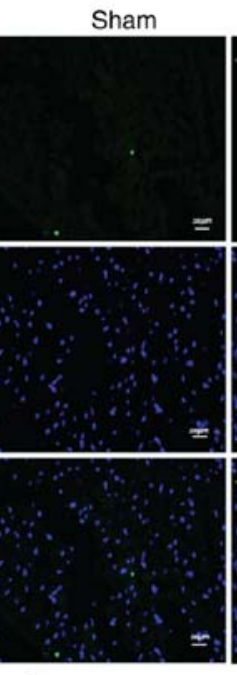

.

$48 \mathrm{~h}$
B

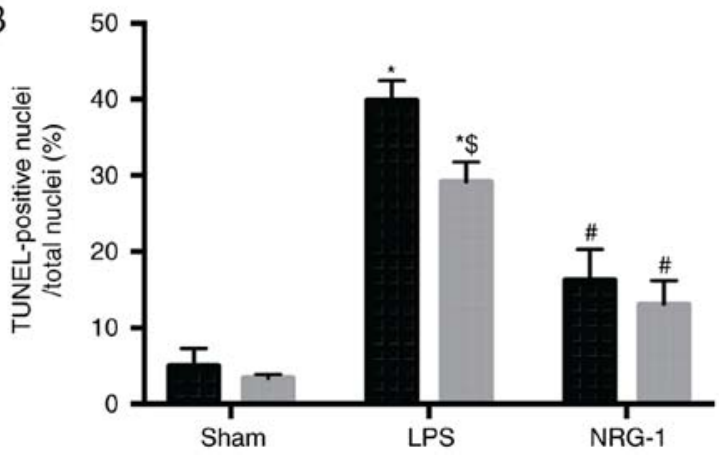

$24 \mathrm{~h}$

$48 \mathrm{~h}$

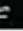

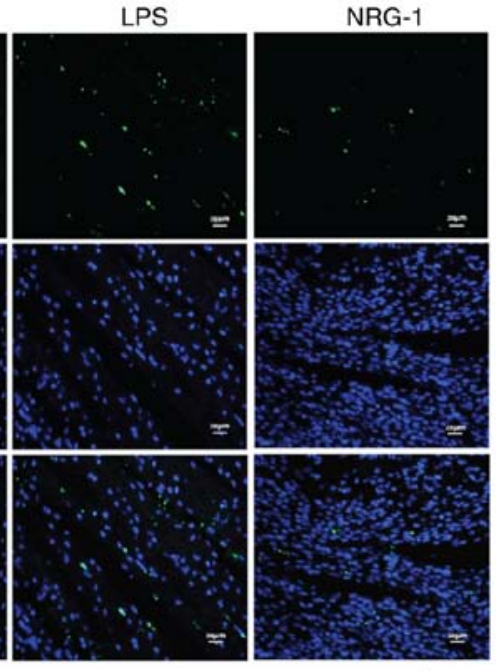

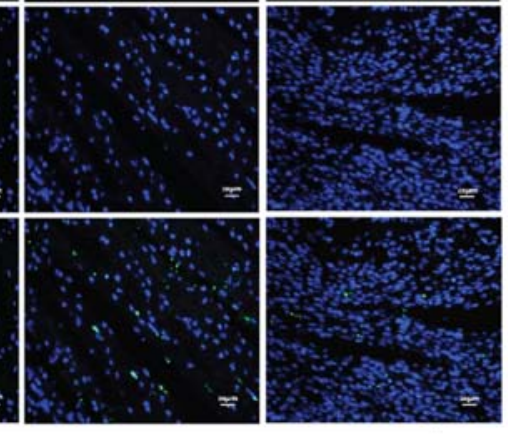
indicates TUNEL-positive nuclei; blue color indicates DAPI signals. Magnification, $\mathrm{x} 400, \mathrm{n}=5$, five fields for each specimen, bars $=20 \mu \mathrm{m}$. (B) Percentages of apoptotic cells in endothelial cells for all treatment groups. Data are presented as the mean \pm standard deviation. ${ }^{*} \mathrm{P}<0.05$ vs. sham group; ${ }^{*} \mathrm{P}<0.05$ vs. LPS group; ${ }^{\mathrm{S}} \mathrm{P}<0.05$ vs. $24 \mathrm{~h}$ group. TUNEL, terminal deoxynucleotidyl-transferase-mediated dUTP nick end labelling assay; LPS, lipopolysaccharide; NRG-1, neuregulin-1.

regulation (18). Effectively reducing the production of cell adhesion molecules and other vascular endothelial biomarkers in blood may serve a strong protective function against vascular endothelial function (19).

In the present study, LPS was selected to induce sepsis in a rat model. LPS is able to directly damage vascular ECs. On one hand, the effects of histamine, bradykinin and leukotriene cause the contraction of vascular ECs; on the other hand, the release of a series of myocardial depressant substances, including TNF- $\alpha$ and IL-6, may cause the remodeling of the EC skeleton (18). These two effects are able to cause an increase in vascular permeability (18). It has been revealed that LPS is able to induce the release various inflammatory mediators and reactive oxygen species by leukocytes, and tissue hypoxia induced by shock may promote the apoptosis of ECs (19). Apoptotic cells release ICAM-1 and vascular cell adhesion protein 1 (VCAM-1), which may aggravate the inflammatory reaction and impair the function of ECs (20). LPS results in the release of a large number of inflammatory factors and EC adhesion molecules (including ICAM-1 and VCAM-1) by ECs (18). In turn, this process causes further cell damage and dysfunction, resulting in the loss of vascular EC barrier function, myocardial ischemia, hypoxia and even disseminated intravascular coagulation and ultimately, multiple organ
Table III. Levels of TNF- $\alpha$ and IL-6 in the sera of rats for each treatment group.

\begin{tabular}{lcc}
\hline & TNF- $\alpha(\mathrm{pg} / \mathrm{ml})$ & IL-6 $(\mathrm{pg} / \mathrm{ml})$ \\
\hline Sham 24 h & $3.08 \pm 0.66$ & $3.19 \pm 1.11$ \\
Sham 48 h & $7.72 \pm 0.70$ & $10.41 \pm 1.23$ \\
LPS 24 h & $13.56 \pm 3.32$ & $491.66 \pm 77.86^{\mathrm{a}}$ \\
LPS 48 h & $31.28 \pm 5.11^{\mathrm{a}, \mathrm{b}}$ & $1,209.35 \pm 28.21^{\mathrm{a}, \mathrm{b}}$ \\
NRG-1 24 h & $4.77 \pm 0.23$ & $21.30 \pm 6.35^{\mathrm{c}}$ \\
NRG-1 48 h & $3.32 \pm 0.64^{\mathrm{c}}$ & $596.27 \pm 53.75^{\mathrm{b}, \mathrm{c}}$
\end{tabular}

Data are presented as the mean \pm standard deviation $(\mathrm{n}=6) .{ }^{\mathrm{a}} \mathrm{P}<0.05 \mathrm{vs}$. sham group; ${ }^{b} \mathrm{P}<0.05$ vs. 24 h group; ${ }^{c} \mathrm{P}<0.05$ vs. LPS group. TNF- $\alpha$, tumor necrosis factor $\alpha$; IL-6, interleukin 6; LPS, lipopolysaccharide; NRG-1, neuregulin-1.

dysfunction, shock and mortality $(18,19)$. In an LPS-induced injury model of human umbilical vein ECs, IL-6 and TNF levels were substantially upregulated subsequent to LPS stimulation, and EC injury was attenuated following glucoside treatment. At the same time, the levels of inflammatory factors 


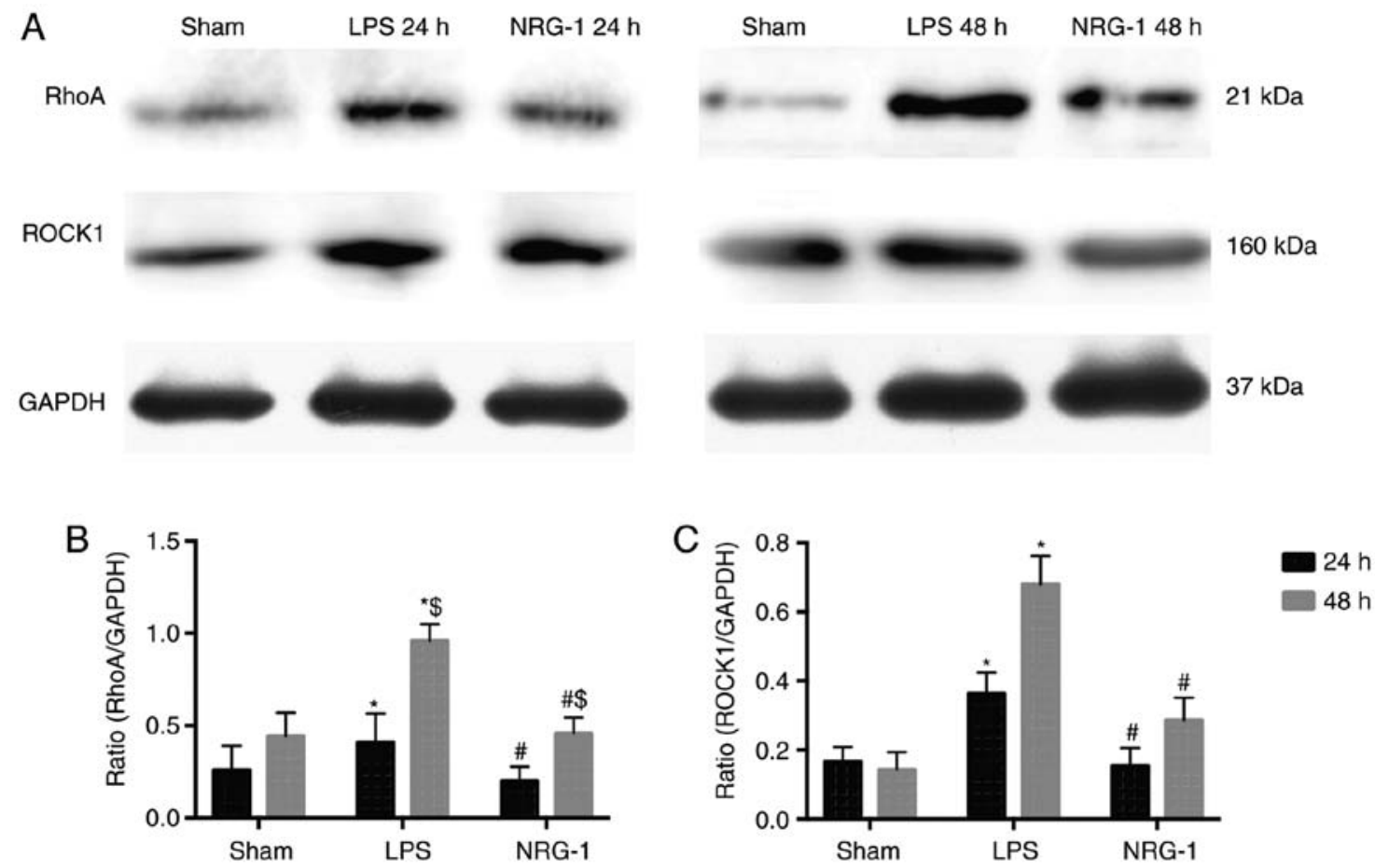

Figure 7. Western blot analysis was performed to examine the RhoA/ROCK signaling pathway in the different treatment groups of rats. (A) RhoA and ROCK1 protein expression in the myocardium. (B) Comparison of quantified RhoA expression levels in the myocardium across the different treatment groups. (C) Comparison of quantified ROCK1 expression levels in myocardium across the different treatment groups. $\mathrm{n}=3$. Data are presented as the mean \pm standard deviation. " $\mathrm{P}<0.05$ vs. sham group; ${ }^{*} \mathrm{P}<0.05$ vs. LPS group; ${ }^{\mathrm{S}} \mathrm{P}<0.05$ vs. $24 \mathrm{~h}$ group. RhoA, ras homolog family member $\mathrm{A}$; ROCK1, Rho-associated protein kinase 1; LPS, lipopolysaccharide; NRG-1, neuregulin-1.
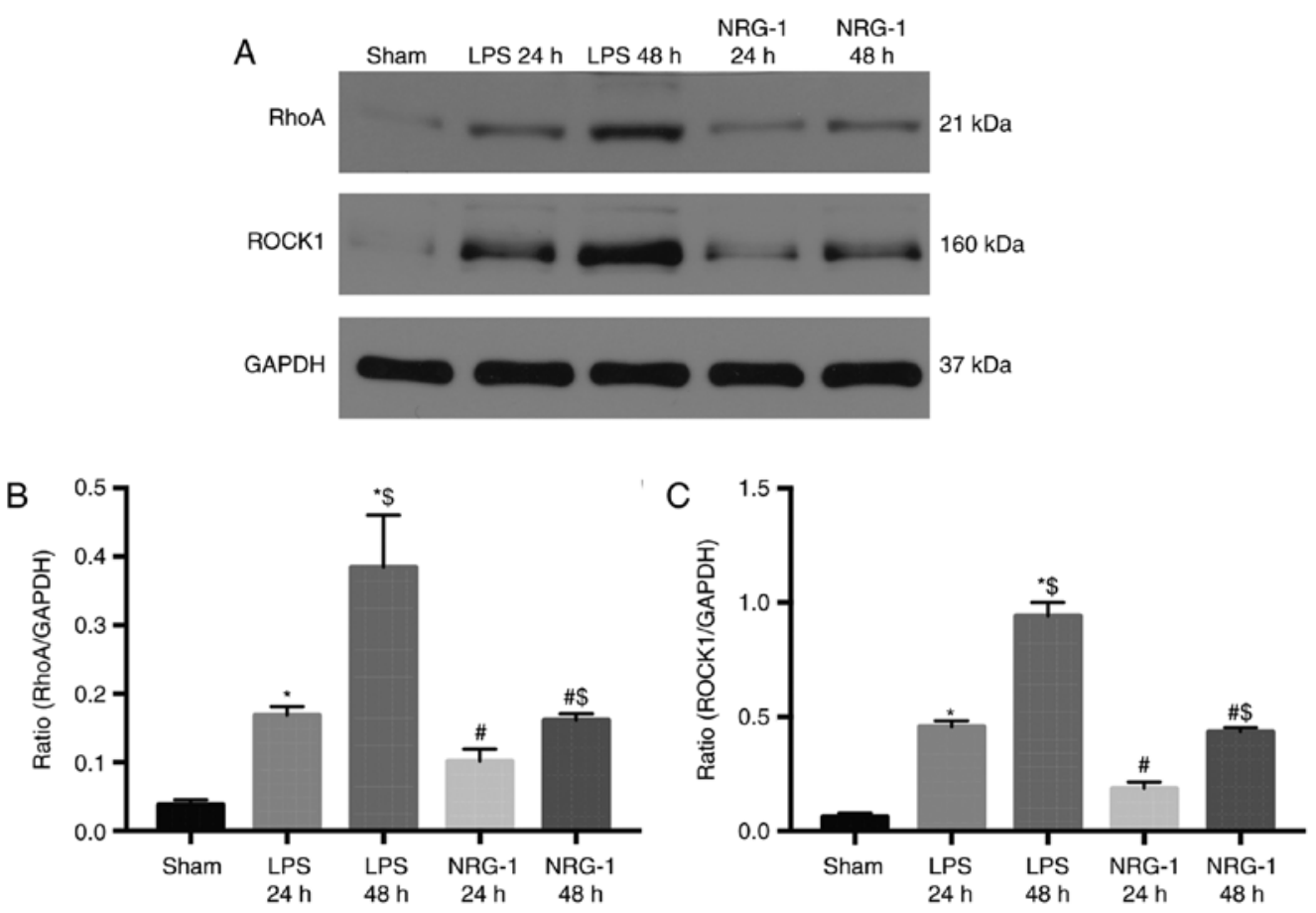

Figure 8. Western blot analysis was performed to examine the RhoA/ROCK signaling pathway in vitro. (A) RhoA and ROCK1 protein expression in H9c2 cells. (B) Comparison of quantified RhoA expression levels in H9c2 cells across the different treatment groups. (C) Comparison of quantified ROCK1 expression levels in $\mathrm{H} 9 \mathrm{c} 2$ cells across the different treatment groups. $\mathrm{n}=3$. Data are presented as the mean \pm standard deviation. ${ }^{*} \mathrm{P}<0.05$ vs. sham group; ${ }^{\sharp} \mathrm{P}<0.05$ vs. LPS group; ${ }^{\mathrm{S}} \mathrm{P}<0.05$ vs. $24 \mathrm{~h}$ group. RhoA, ras homolog family member A; ROCK1, Rho-associated protein kinase 1; LPS, lipopolysaccharide; NRG-1, neuregulin-1.

expressed in ECs were reduced (21). The results of the present study revealed that the serum levels of the pro-inflammatory cytokines TNF- $\alpha$ and IL- 6 were partially restored following
rhNRG-1 treatment. These preliminary results demonstrate the inhibitory effect of rhNRG-1 on the immune inflammatory response. 
The biomarkers that are used at present to evaluate the activation or functional impairment of ECs include ICAM-1, VCAM-1, VEGF and vWF (18-21). Biomarker levels are positively associated with the degree of injury of ECs (18-21). Previous studies have demonstrated that $72 \mathrm{~h}$ after septic induction in rats, the serum levels of ICAM-1 and vWF were significantly upregulated; however, simvastatin treatment alleviated the injury of vascular ECs $(22,23)$. The results of the present study indicated that ICAM-1 and VEGF levels were significantly upregulated in the LPS group compared with those in the sham group $(\mathrm{P}<0.05)$. However, the observed increase was reversed by rhNRG-1 treatment. During sepsis, the levels of the endocrine vasodilator NO increase, resulting in abnormal vasoconstriction and relaxation, insufficient circulatory perfusion, tissue ischemia and hypoxia, which further amplify septic shock (15). These processes are closely associated with cardiac dysfunction (15). The present results revealed that NO levels were significantly reduced following rhNRG-1 treatment compared with the LPS group $(\mathrm{P}<0.05)$.

Increased permeability and loss of barrier function are the core features that characterize EC dysfunction during sepsis (3), thereby causing organ dysfunction and further triggering MODS. Yano et al (24) revealed that in the LPS model, the vascular permeabilities of the lungs and kidneys are substantially increased. The present study measured vWF levels to assess the integrity of the endothelium, given that it is abundant in the ECs and that the circulating level of vWF has been used as a biomarker for endothelial damage/dysfunction in various disease states, including systemic inflammatory response syndrome, atherosclerosis, hypertension and diabetes (25). Kwon et al (26) demonstrated that patients exhibited weaker vWF immunostaining along the endothelial lining compared with those who recovered from acute respiratory failure. Similarly, vWF levels around the endothelial lining were higher in the NRG-1 group. The present study demonstrated that vWF immunostaining along the endothelial lining was significantly decreased in the LPS group compared with that in the sham group; however, the observed decrease was improved by rhNRG-1 treatment.

The further sequence of pathogenesis of septic endothelial dysfunction is the elimination or inhibition of NO (27). In clinical trials using patients with sepsis, methylene blue (no scavenger) has been demonstrated to attenuate hemodynamic changes (27). An inducible NO synthase inhibitor (L-Kanavanin) may prevent the decrease in myocardial contractility in septic rats (27). NO directly affects the release of vascular tension and pro-inflammatory cytokines (27). In addition, NO may induce the production of apoptotic or anti-apoptotic signals (27). Numerous cytokines serve key functions in the inflammatory response and partly regulate myocardial function through NO generation (3-5). A study have been documented in patients with left ventricular dysfunction and septic mice, a decreased adrenergic response is associated with elevated NO levels (27). All the abovementioned changes affect the cardiac function of septic rats. The present results revealed that NO levels and the number of apoptotic cells were significantly higher in the LPS group compared with those in the sham group $(\mathrm{P}<0.05)$. The present results suggested that rhNRG-1 attenuates excessive oxidative stress and apoptosis.
The mortality caused by sepsis is most commonly attributed to cardio-circulatory depression (22). The present study selected rats at 24 and $48 \mathrm{~h}$ following LPS-induction to observe, as they reflected changes in the process of cardiac dysfunction in sepsis. Previous studies suggest that NRG-1 improves cardiac function and protects rat cardiomyocytes from cecal ligation and puncture (CLP)-induced sepsis by suppressing the immune inflammatory response and inhibiting the excessive activation of the renin-angiotensin-aldosterone system. NRG-1 was revealed to increase the survival rates of rats in an CLP-induced sepsis model at $24 \mathrm{~h}$ (21). In the present study, rats subjected to LPS exhibited cardio-circulatory depression (impaired MAP, dp/dt and LVP generation; Fig. 2) and histological and cytological (Fig. 5) changes due to myocardial cell damage. The results revealed that rhNRG-1 may alleviate EC dysfunction, in addition to improving the cardiac function and survival of rats at $48 \mathrm{~h}$ after sepsis induction.

NRG-1 is synthesized and released by the endocardial and cardiac microvascular endothelium (12). A previous study revealed that NRG-1 was able to improve left ventricular function and increase capillary density in diabetic cardiomyopathy (DCM) (28). NRG-1 had been demonstrated to alleviate diastolic dysfunction in animal models of DCM and angiotensin II-induced injury (28). In vitro experiments revealed that NRG-1 treatment may upregulate VEGF expression in human coronary artery smooth muscle cells. The NRG-1/ErbB system is required for the physiological adaptation of the heart to the changes of cardiac demand $(29,30)$. One previous study reported that NRG-1 may improve cardiac function in animal models of heart disease, including ischemic, dilated and viral cardiomyopathy (29). NRG-1 exerts beneficial effects on cardiac function and is known to regulate the metabolic activity of cardiomyocytes and maintain cardiac homeostasis. For instance, NRG-1 administration was demonstrated to restore mitochondrial function and reduce oxidative stress (30). A previous study has confirmed that rhNRG-1 is able to inhibit the excessive activation of pro-inflammatory factors in the early stage of sepsis-induced cardiomyopathy and help prevent myocardial injury in the late stage via cardio-protective mechanisms (12). However, further studies are required. ClinicalTrials.gov has also listed a number of cardiac therapies involving NRG-1 administration (31). Thus, it was hypothesized that NRG-1 administration may be effective in treating sepsis-induced cardiomyopathy via its multiple cardio-protective effects.

Activation of the RhoA/ROCK signaling pathway reduces NO availability, upregulates the expression of the leukocyte adhesion factor ICAM-1 and participates in various inflammatory responses $(30,32-34)$. In addition, RhoA/ROCK signaling causes EC shedding, increases serum levels of vWF and increases the permeability of the vascular endothelium (35). RhoA activation has been demonstrated to be involved in oxidative stress (30). ROCK regulates the development of cardiovascular diseases by inducing the expression of $\mathrm{NO}$ synthase in ECs (32). Insufficient NO production in vascular ECs results in impaired endothelium-dependent vasodilation (33). Furthermore, inhibition of the RhoA/Rho-kinase pathway activates NO production and attenuates vascular inflammation (34). NRG-1-induced tumor cell motility is known to negatively regulate ROCK signaling (36). A previous study demonstrated that the activation of RhoA/Rho kinase 
signaling promotes VEGF-induced in vitro EC migration, angiogenesis and cytoskeletal changes; by contrast, the inhibition of Rho kinase prevented mechanical wounding (37). The RhoA/ROCK pathway induces thrombin-induced ICAM-1 expression via the activation of IкB kinase (38) and exacerbates LPS-induced endothelial hyper-permeability by mediating the formation of stress fibers in ECs. Therefore, inhibition of RhoA/ROCK activation may improve vascular hyper-permeability in sepsis (39). Next, the present study investigated the protein expression levels of RhoA and ROCK1 at 24 and $48 \mathrm{~h}$ after sepsis (Fig. 7), and the results revealed that rhNRG-1 is able to suppress the expression of RhoA and ROCK1 in vivo and in vitro, indicating that NRG-1 functioned in the regulation of the anti-inflammatory and anti-oxidative stress action, which is based on the RhoA/ROCK pathway.

The results of the present study revealed that NRG-1 may alleviate the injury of ECs, improve cardiac function and protect the integrity of ECs by inhibiting the secretion of EC adhesion molecules, vascular endothelial growth factor and other endothelial-associated biomarkers and inflammatory factors. NRG-1 inhibits oxidative stress and apoptosis and strengthens the barrier function of vascular tissue, thereby improving cardiac function and increasing survival rates via multiple targets. NRG-1 exerts protective effects on the vascular endothelium by reducing VEGF levels, subsequently preventing VEGF-mediated activation of the RhoA/ROCK signaling pathway. These results suggest that NRG-1 may improve its secretory function and the permeability of cardiac ECs, which may be mediated by the RhoA/ROCK signaling pathway. The above results may serve as the basis for the development of a novel approach to reverse the impaired vascular ECs in sepsis in future studies.

At present, the primary treatments for sepsis-induced cardiac dysfunction primarily focus on hemodynamics, infections and energy supply (40). The present study revealed that NRG-1 improved cardiac dysfunction via multiple targets, alleviating the excessive activation of inflammatory responses and alleviating the injury of ECs. These observations may serve as a basis for the development of a novel approach to reverse the impairment of vascular ECs in sepsis in future studies.

\section{Acknowledgements}

Not applicable.

\section{Funding}

The present study was supported by the National Natural Science Foundation of China (grant nos. 81772044 and 81500255), the Program for Innovative Research Team in Hainan Province (grant no. 2016CXTD012), the Science Foundation of Wuhan Health and Family Planning Commission (grant no. WX17B09), the Natural Science Foundation of Hubei Province (grant no. 2017CFC824) and Wuhan University Young Teachers Project (grant nos. 2042018kf0199 and 2042017kf0138).

\section{Availability of data and materials}

All data generated or analyzed during the current study are included in this published article.

\section{Authors' contributions}

WK , LW and XiW conceived and designed the study. WK, YC, LZ and HTL conducted the experiments and wrote the manuscript. WK, SD, FZ and XinW analyzed the data. WK, LW, XiW, LZ and HTL revised the manuscript. All the authors read and approved the final manuscript.

\section{Ethics approval and consent to participate}

The animal experiments and procedures were ethically approved by the Animal Care and Use Committee of Renmin Hospital of Wuhan University (Wuhan, China). All protocols were performed in accordance with the US National Institutes of Health guide for the care and use of Laboratory animals (National Institutes of Health Publication revised in 2011) (40). All animal studies also complied with the Animal Research: Reporting of In Vivo Experiments guidelines and the American Veterinary Medical Association's euthanasia guidelines of $2013(41,42)$.

\section{Patient consent for publication}

Not applicable.

\section{Competing interests}

The authors declare that they have no competing interests.

\section{References}

1. Seymour CW, Liu VX, Iwashyna TJ, Brunkhorst FM, Rea TD, Scherag A, Rubenfeld G, Kahn JM, Shankar-Hari M, Singer M, et al: Assessment of clinical criteria for sepsis. For the third international consensus definitions for sepsis and septic shock (Sepsis-3). JAMA 315: 762-774, 2016.

2. Opal SM and van der Poll T: Endothelial barrier dysfunction in septic shock. J Internal Med 277: 277-293, 2015.

3. Boonla O,Kukongviriyapan U,PakdeechoteP,Kukongviriyapan V, Pannangpetch P, Prachaney P and Greenwald SE: Curcumin improves endothelial dysfunction and vascular remodeling in $2 \mathrm{~K}-1 \mathrm{C}$ hypertensive rats by raising nitric oxide availability and reducing oxidative stress. Nitric Oxide 42: 44-53, 2014.

4. Park MH, Heo SJ, Park PJ, Moon SH, Sung SH, Jeon BT and Lee SH: 6,6'-Bieckol isolated from ecklonia cava protects oxidative stress through inhibiting expression of ROS and proinflammatory enzymes in high-glucose-induced human umbilical vein endothelial cells. Appl Biochem Biotechnol 174: 632-643, 2014.

5. Reverri EJ, Morrissey BM, Cross CE and Steinberg FM: Inflammation, oxidative stress, and cardiovascular disease risk factors in adults with cystic fibrosis. Free Radic Biol Med 76: 261-277, 2014.

6. Leligdowicz A, Richard-Greenblatt M, Wright J, Crowley VM and Kain KC: Endothelial activation: The Ang/Tie axis in sepsis. Front Immunol 9: 838, 2018.

7. Liu M, Solomon W, Cespedes JC, Wilson NO, Ford B and Stiles JK: Neuregulin-1 attenuates experimental cerebral malaria (ECM) pathogenesis by regulating ErbB4/AKT/STAT3 signaling. J Neuroinflamm 15: 104, 2018.

8. Howell MD and Davis AM: Management of sepsis and septic shock. JAMA 317: 847-848, 2017.

9. Xiao J, Li B, Zheng Z, Wang M, Peng J, Li Y and Li Z: Therapeutic effects of neuregulin-1 gene transduction in rats with myocardial infarction. Coron Artery Dis 23: 460-468, 2012.

10. Parodi EM and Kuhn B: Signaling between microvascular endothelium and cardiomyocytes through neuregulin. Cardiovasc Res 102: 194-204, 2014.

11. Orlandi A and Bennett M: Progenitor cell-derived smooth muscle cells in vascular disease. Biochem pharmacol 79: 1706-1713, 2010. 
12. Zhou Q, Pan X, Wang L, Wang X and Xiong D: The protective role of neuregulin-1: A potential therapy for sepsis-induced cardiomyopathy. Eur J Pharmacol 788: 234-240, 2016.

13. Lenihan DJ, Anderson SA, Lenneman CG, Brittain E, Muldowney JAS III, Mendes L, Zhao PZ, Iaci J, Frohwein S, Zolty R, et al: A phase I, single ascending dose study of cimaglermin alfa (neuregulin 1 133 ) in patients with systolic dysfunction and heart failure. JACC Basic Transl Sci 1: 576-586, 2016.

14. National Research Council (US) Committee for the Update of the Guide for the Care and Use of Laboratory Animals.: Guide for the Care and Use of Laboratory Animals. 8th edition. National Academies Press (US), Washington, DC, 2011.

15. Liao MH, Shih CC, Tsao CM, Chen SJ and Wu CC: RhoA/Rho-kinase and nitric oxide in vascular reactivity in rats with endotoxaemia. PLoS One 8: e56331, 2013.

16. Hotchkiss RS and Karl IE: The pathophysiology and treatment of sepsis. N Engl J Med 348: 138-150, 2003.

17. Candel FJ, Borges Sá M, Belda S, Bou G, Del Pozo JL, Estrada O, Ferrer R, González Del Castillo J, Julián-Jiménez A, Martín-Loeches I, et al: Current aspects in sepsis approach. Turning things around. Rev Esp Quimioter 31: 298-315, 2018.

18. Lee J, Lee S, Zhang H, Hill MA, Zhang C and Park Y: Interaction of IL-6 and TNF- $\alpha$ contributes to endothelial dysfunction in type 2 diabetic mouse hearts. PLoS One 12: e0187189, 2017.

19. Qi D, Wang D, Zhang C, Tang X, He J, Zhao Y, Deng W and Deng X: Vaspin protects against LPS-induced ARDS by inhibiting inflammation, apoptosisand reactive oxygen species generation in pulmonary endothelial cells via the Akt/GSK-3 $\beta$ pathway. Int J Mol Med 40: 1803-1817, 2017.

20. Stefanec T: Endothelial apoptosis: Could it have a role in the pathogenesis and treatment of disease. Chest 117: 841-854, 2000

21. Ma MM, Li Y, Liu XY, Zhu WW, Ren X, Kong GQ, Huang X, Wang LP, Luo LQ and Wang XZ: Cyanidin-3-O-Glucoside ameliorates lipopolysaccharide-induced injury both in vivo and in vitro suppression of NF-kB and MAPK pathways. Inflammation 38: 1669-1682, 2015.

22. Sakuragi T, Lin X, Metz CN, Ojamaa K, Kohn N, Al-Abed Y and Miller EJ: Lung-derived macrophage migration inhibitory factor in sepsis induces cardio-circulatory depression. Surg Infect (Larchmt) 8: 29-40, 2007

23. Jiang S, Li S, Hu J, Xu X, Wang X, Kang X, Qi J, Lu X, Wu J, Du Y and Xiao Y: Combined delivery of angiopoietin-1 gene and simvastatin mediated by anti-intercellular adhesion molecule-1 antibody-conjugated ternary nanoparticles for acute lung injury therapy. Nanomedicine 15: 25-36, 2019.

24. Yano K, Liaw PC, Millington JM, Shih SC, Okada H, Bodyak N, Kang PM, Toltl L, Belikoff B, Buras J, et al: Vascular endothelial growth factor is an important determinant of sepsis morbidity and mortality. J Exp Med 203: 1447-1458, 2006.

25. Jacobson SH, Egberg N, Hylander B and Lundahl J: Correlation between soluble markers of endothelial dysfunction in patients with renal failure. Am J Nephrol 22: 42-47, 2002.

26. Kwon O, Hong SM, Sutton TA and Temm CJ: Preservation of peritubular capillary endothelial integrity and increasing pericytes may be critical to recovery from postischemic acute kidney injury. Am J Physiol Renal Physiol 295: F351-F359, 2008.

27. Barth E, Radermacher P, Thiemermann C, Weber S, Georgieff M and Albuszies G: Role of inducible nitric oxide synthase in the reduced responsiveness of the myocardium to catecholamines in a hyper dynamic, murine model of septic shock. Crit Care Med 34: 307-313, 2006.
28. Hervent AS, Vandekerckhove L and Keulenaer GWD: Neuregulin-1 antagonizes myocardial fibrosis and diastolic dysfunction in angiotensin-II treated mice. Eur Heart J 34: 24-34, 2013.

29. Turner A, Tsamitros M and Bellomo R: Myocardial cell injury in septic shock. Crit Care Med 27: 1775-1780, 1999.

30. Guo LW, Gao L, Rothschild J, Su B and Gelman IH: Control of protein kinase $\mathrm{C}$ activity, phorbol ester-induced cytoskeletal remodeling, and cell survival signals by the scaffolding protein SSeCKS/GRAVIN/AKAP12. J Biol Chem 286: 38356-38366, 2011.

31. Galindo CL, Ryzhov S and Sawyer DB: Neuregulin as a heart failure therapy and mediator of reverse remodeling. Curr Heart Fail Rep 11: 40-49, 2015.

32. Siafakas NM, Antoniou KM and Tzortzaki EG: Role of angiogenesis and vascular remodeling in chronic obstructive pulmonary disease. Int J Chron Obstruct Pulmon Dis 2: 453-462, 2007.

33. Mount PF, Kemp BE and Power DA: Regulation of endothelial and myocardial NO synthesis by multi-site eNOS phosphorylation. J Mol Cell Cardiol 42: 271-279, 2007.

34. Sawada N and Liao JK: Targeting eNOS and beyond: Emerging heterogeneity of the role of endothelial Rho proteins in stroke protection. Expert Rev Neurother 9: 1171-1186, 2009.

35. Li D, Cheng P, Jiang H, Cao T, Wang J, Gao Y, Lin Y, Wang C, Zhang S, Li J, et al: Vascularization converts the lineage fate of bone mesenchymal stem cells to endothelial cells in tissue-engineered bone grafts by modulating FGF2-RhoA/ROCK signaling. Cell Death Dis 9: 959, 2018.

36. Rana MK and Worthylake RA: Novel mechanism for negatively regulating Rho-kinase (ROCK) signaling through Coroninlb protein in neuregulin 1 (NRG-1)-induced tumor cell motility. J Biol Chem 287: 21836-21845, 2012.

37. van Nieuw Amerongen GP, Koolwijk P, Versteilen A and van Hinsbergh VW: Involvement of RhoA/Rho kinase signaling in VEGF-induced endothelial cell migration and angiogenesis in vitro. Arterioscler Thromb Vasc Biol 23: 211-217, 2003.

38. Anwar KN, Fazal F, Malik AB and Rahman A: RhoA/Rhoassociated kinase pathway selectively regulates thrombin-induced intercellular adhesion molecule-1 expression in endothelial cells via activation of I kappa B kinase beta and phosphorylation of RelA/p65. J Immunol 173: 6965-6972, 2004.

39. Zhou Z, Guo F, Dou Y, Tang J and Huan J: Guanine nucleotide exchange factor-H1 signaling is involved in lipopolysaccharideinduced endothelial barrier dysfunction. Surgery 154: 621-631, 2013.

40. Chen J, Lai J, Yang L, Ruan G, Chaugai S, Ning Q, Chen C and Wang DW: Trimetazidine prevents macrophage-mediated septic myocardial dysfunction via activation of the histone deacetylase sirtuin 1. Br J Pharmacol 173: 545-561, 2016.

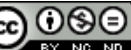

This work is licensed under a Creative Commons Attribution-NonCommercial-NoDerivatives 4.0 International (CC BY-NC-ND 4.0) License. 